men directly after confinement, M. Le Groux, of the Hôtel Dieu, is quoted as adopting the views now pretty general here, and especially insisted on by Dr. Graily Hewitt, in giving meat and soup.

In the chapter on abortion, repeated small venesections are recommended as a prophylactic, where the patient is plethoric, and powdered savine when she is anæmic.

In contraction of the pelvis, M. Tarnier gives 2 5-8 inches as the least diameter compatible with safe delivery. Churchill states that a living child cannot pass through a pelvic whose small diameter is less than three inches.

In unavoidable hæmorrhage M. Tarnier would plug, and wait; and, secondly, if necessary, rupture the membranes.

Dr. Barnes's views as to the development of the placenta and its zonic attachments, on which he founds his treatment of unavoidable hæmorrhage, are not alluded to, though M. Tarnier seems well acquainted with his uterine dilator, which instrument M. Tarnier uses in conjunction with one of his own invention where premature labor is to be induced.

M. Tarnier's instrument consists of a gum elastic catheter, the upper end of which being made with thin walls, dilates into a ball when filled with water or air. This he passes with a guide into the uterus. The ball prevents its expulsion, and the ovular membranes remain unbroken. As soon as the cervix admits, M. Tarnier introduces Barnes's dilator. The other obstetric operations, as the use of the forceps, vectis, cephalotribe, with M. Pajot's method of "repeated cephalotripsy without traction," Casarean section, \&c., are fully described.

M. Tarnier has most ably put the finishing touches to Cazeaux's description of albuminuria during pregnancy, and its connection with eclampsia; he sums up the causes of albuminuria as arising from either -1. Super-alburninosis of the blood, for though the albumen is diminished relatively to the mass of the other constituents, there is a marked predominance of albumen as compared with the corpuscles (Gubler); or-2. Over distention of the renal vessels; or-3. Albuminous nephritis, which may be either primary or secondary.

Mrr. Geo. F. Markoe, an expert Buston chemist, has produced hydrate of chloral more beantifully crystallized than any of the imported samples which have come to our notice. - N. Y. Medical Gazelle.

\section{TRANSFUSION OF BLOOD.}

Report of a Vivisection, illustrating Lectures on the Blood, by Prof. Freer, Rush Medical College. Reported by F. L. Wadsworti, M.D., Chicago, Ill.

The following account of a vivisection, performed before the class, at Rush Medical College, on the 10th Dec., by Dr. Freer, Professor of Physiology and Microscopic Anatomy, may be of value to your readers.

A dog, the weight of which was fourteen pounds avoirdupois, was anæsthetized, the left carotid artery and jugular veins were exposed, a canula inserted into each, and secured by ligatures. Sufficient time was then allowed for the animal to recover his consciousness from the effects of the anæsthetic, when the stop-cock of the canula inserted into the artery was turned, and the blood allowed to flow until sixteen ounces were extracted and the force of the heart's pulsations so reduced that no more could be drawn from the artery with the animal lying horizontally upon his right side. Respiration now gave evidence of syncope, the limbs were rigid, the jaws set, death was impendent.

Meantime, a portion of the blood drawn had been defibrinated and kept at its normal temperature, by a warm water bath. It was now (twenty minutes from the time it commenced to flow from the artery) passed through the canula, by means of a syringe, into the jugular vein. In this manner seven ounces of defibrinated blood were returned to the system of the animal.

On the introduction of the first ounce there was observed decided evidence of increased vigor. During the injection of the second ounce, by some defect in the apparatus, air was admitted into the vein. Instantly the animal succumbed; a tremor affected his entire system, and respiration ceased. Prof. Freer remarked that the animal's life had been sacrificed by the accident ; but by convulsive efforts he regained respiration, and in two or three minutes the effects of the occurrence had disappeared. When the seventh ounce had been introduced there remained little, if any, disturbance of respiration, the heart's vigor was nearly restored, the muscular spasm had subsided, and there was apparently no more disturbance of the system than usually occurs at this period after the administration of chloroform for any ordinary operation.

In eight minutes after the blood had been returned the animal raised his head and observed intelligently; and twelve minutes thereafter he voluntarily raised himself and walked across the room, some twelve or 
fifteen feet. The day following he was sprightly and playful, and the second day after the operation he travelled nearly a quarter of a mile without any evidence of fatigue whatever.

This vivisection occurred during the delivery of a lecture on the blood, by Prof. Freer, and was introduced to illustrate the function of the red blood corpuscles in their immediate relations to respiration and the mainteuance of vitality, and to demonstrate the fact that fibrin takes no immediate part in restoration from exhaustive hæmorrhage, serum serving as the vehicle of the vitalizing corpuscle, and that transfusion with defibrinated blood may be performed somewhat leisurely and with impunity, care being taken that the instruments used are nicely adapted for the exclusion of air from the vessels. - Chicago Medical Journal.

\section{TNE INTERNATIONAL MEDICAL CONGRESS AT FLORENCE.}

[From the Dublin Medical Press and Circular we take the following account, by a special correspondent of that journal, of the proceedings of the International Medical Congress during its recent session at Florence.]

The Medical Congress met on the $23 \mathrm{~d}$ instead of the 20th of September, as a meeting of medical men and scientific people was still going on at Innspruck on the 20th. To repay for the loss of time, it was settled that every day two sittings should be held -one, according to the questions of the programme, in the morning, and a second in the afternoon, upon free subjects. It would be impossible, and perhaps useless, to report all the details of those sittings, but I suppose that it may prove interesting to English physicians to hear something concerning the most important subjects which were discussed during the session.

The first subject, and whioh, as the most interesting, occupied four full morning sittings, was the one of marsh-miasma, its origin, its nature, and what are the best means to destroy, or at least to counteract it. Dr. Pantaleoni, who first treated generally the subject, and others like Dr. Umara, Dr. Spaturri, Dr. Mingrona, gave details about the miasma of Sardinia, of the valley of the Liris, and of the Brutian countries. It is really admirable the accord existing amongst Italian physicians about the laws which rule the development of the palustrian miasma. They all agree on the laws promulgated by Dr. Pantaleoni, that the miasma rises not only from marshes, but also from land newly excavated; that it does not rise very high from the surface of the ground, but it may be carried by the winds to a great distance, and so infect distant villages and towns more than those which, sheltered from the wind, lay near the marsh itself. They all agree that an amount of heat, mixed chiefly with dampness, is necessary for the creation and development of the miasma, which otherwise is nowbere to be found; but where are vegetables is putrefaction; cryptogams in formation, either from the fungous deposits of the marsh, or by stagnant waters on newly excavated earth. So Dr. Pantaleoni concluded that the palustrian miasma is of a vegetable origin, almost as surely as the one of typhus and typhoid is of an animal origin, and therefore two quite different sets of fever, the last generally catching, and the others completely deprired of the contagious or infectious nature. Dr. Pantaleoni went even furtber, proposing, as a most probable hypothesis, that the miasma should be considered as a real plant, a kind of alga, whose spores, carried in the air, should produce the affection. He had determined to undertake some experiments upon the subject in the Pontine marshes, and bad invited Dr. Balestra, of Rome, to help him. Howerer, Dr. Balestra had on his own account entered on the same line of most interesting experiments, by which he has shown that the fog and the air of marshes is infested with myriads of spores from an alga peculiar to the marshes, and which be named febrigenica, and Dr. Pantaleoni pyretogenica; that the influence is in proportion to the development of those spores ; that by inhaling or drinking them in water, the ague is almost always produced ; and that the application of a solution of quinine kills those alga in twelve to twenty hours; an arsenical solution is less active, and the sulphites even less. The infusoria or animalculæ exist in the transported air, although they exist in the fog of the marshes.

These particulars separate immediately Dr. Balestra's (of Rome) experiments from those of Dr. Salisbury of the United States, as this last saw animals and spores. He attributed the affection to a palmella,.which is demonstrated to be impossible, and then never saw quinine acting upon it. $\mathrm{Dr}$. Balestra's observations coufirmed so well the proposition of Dr. Pantaleoni, that a vote of the Congress was presented, to state that the existence of those cryptogams as a cause of miasma was a real discovery; but 